\title{
A novel format for recombinant antibody-interleukin-2 fusion proteins exhibits superior tumor-targeting properties in vivo
}

\author{
Tiziano Ongaro ${ }^{1,2}$, Baptiste Gouyou ${ }^{1}$, Marco Stringhini ${ }^{3}$, Riccardo Corbellari ${ }^{1,4}$, \\ Dario Neri ${ }^{3}$ and Alessandra Villa ${ }^{1}$ \\ ${ }^{1}$ Philochem AG, Otelfingen, Switzerland \\ ${ }^{2}$ University School for Advanced Studies IUSS Pavia, Pavia, Italy \\ ${ }^{3}$ Department of Chemistry and Applied Biosciences, Swiss Federal Institute of Technology, ETH Zürich, Zürich, Switzerland \\ ${ }^{4}$ University of Trento, CiBIO, Department of Cellular, Computational and Integrative Biology, Trento, Italy \\ Correspondence to: Dario Neri, email: dario.neri@pharma.ethz.ch \\ Alessandra Villa, email: alessandra.villa@philogen.com
}

Keywords: tumor targeting; fibronectin; immunocytokines; interleukin-2; protein engineering

Received: June 11,2020 Accepted: August 17, $2020 \quad$ Published: October 13, 2020

Copyright: ( 2020 Ongaro et al. This is an open access article distributed under the terms of the Creative Commons Attribution License (CC BY 3.0), which permits unrestricted use, distribution, and reproduction in any medium, provided the original author and source are credited.

\section{ABSTRACT}

The targeted delivery of interleukin-2 to the tumor is gaining attention as an avenue to potentiate the action of $T$ and $N K$ cells at the site of disease. We have previously described the fusion of the L19 antibody, specific to the EDB domain of fibronectin, with human interleukin-2, using a non-covalent homodimeric diabody format. Here, we describe four novel formats for the L19-IL2 fusion, featuring different arrangements of antibody and IL2. A comparative quantitative biodistribution analysis in tumor-bearing mice using radioiodinated proteins revealed that the novel format (L19L19-IL2, with the antibody in single-chain diabody format) exhibited the best biodistribution results. In vitro assays on peripheral blood mononuclear cells showed a decrease activation of regulatory T cells when single IL2 domain was used. In vivo, both L19-IL2 and L19L19-IL2 inhibited tumor growth in immunocompetent mouse models of cancer. T-cell analysis revealed similar levels of $\mathrm{CD4}^{+}$and FoxP3 ${ }^{+}$cells, with an expansion of the CD8 ${ }^{+} \mathrm{T}$ cell in mice treated with L19-IL2 and L19L19-IL2. The percentage of $\mathrm{CD4}^{+}$regulatory $\mathrm{T}$ cells was markedly decreased with L19L19-IL2 combined with a mouse-specific PD-1 blocker. Collectively, these data indicate that the new L19L19-IL2 format exhibits favorable tumor-homing properties and mediates a potent anti-cancer activity in vivo.

\section{INTRODUCTION}

There is a growing interest in the use of immunotherapy approaches for the treatment of cancer, which has been promoted by the clinical results obtained against various types of malignancies using anti-PD-1 and anti-PD-L1 antibodies [1-4].

Certain pro-inflammatory cytokines (e.g., interleukin-2) may provide a complementary anti-cancer activity and may be ideal combination partners, in addition not only to immune checkpoint inhibitors $[5,6]$, but also to radiation [7, 8] and cytotoxic agents [9]. IL2 was approved by FDA for metastatic melanoma patients in 1998, based on the observation that a small proportion of subjects enjoyed durable complete responses [10]. However, treatments in these dose regimens often lead to severe side effects, including fever and chills, hypotension, fatigue and vascular leak syndrome, which in extreme cases can lead to organ failure with lethal consequences [11]. Therefore, high dosage treatments are usually reserved to young and physically fit patients only. For this reason, current research efforts aim at the development of IL2 therapeutics with improved therapeutic index. Pegylated forms of IL2 have shown superior properties in mouse models of cancer [12-14] and encouraging results in patients as single agents [15] 
or in combination with anti-PD-1 antibodies [16, 17]. The masking of IL2 epitopes using antibodies allowed the selective activation of lymphocytes sub-populations, improving immune-stimulatory activity [18]. Similar results were achieved by de novo computationally designed IL2 [19].

Various groups [20-22], including our own [23-25], have worked on the concept of fusing the IL2 moiety with suitable tumor-homing antibodies, in order to concentrate the payload at the site of disease, helping spare normal tissues [23]. While some researchers have fused the IL2 moiety at the C-terminal extremity of the heavy chain [21] or of the light chain [26] of antibodies in full IgG format, we have preferred to use antibody fragments, as they may exhibit more favorable tumor: organ ratios and as those products may clear more rapidly from circulation, thus avoiding prolonged cytokinerelated toxicity.

L19 is a fully human, clinical grade antibody that targets the alternatively spliced EDB domain of fibronectin. It reacts with identical affinity toward the human and murine EDB containing fibronectin, allowing an easier translation of experiment in human [27]. EDB is a 91-amino acid domain which is identical in mouse, rat, rabbit dog and man and can be inserted by alternative splicing into the fibronectin molecule [28]. It is expressed during active tissue remodeling and therefore represents an appealing target for the selective delivery of payloads at the tumor site, since it accumulates around neovasculature structures in tumors and is virtually undetectable in healthy organs (exception made for some female reproductive organs) [29, 30]. The value of EDB as target for pharmacodelivery applications has been proven both in preclinical animal models and in patients by quantitative biodistribution studies [31-33], imaging studies with nuclear medicine techniques [34] and in the pharmacodelivery of radionuclides [35].

We have previously developed IL2-based immunocytokines composed of non-covalent homodimeric $\mathrm{scFv}$ fragments delivery vehicle. One of these products, L19-IL2 is currently being evaluated in phase II clinical trials as single immunostimulatory agent [NCT02957019] and phase III in combination with targeted TNF for the of patients with fully resectable stage IIIB, C melanoma [NCT02938299]. In this article, we have investigated four novel formats for the fusion of IL2 to recombinant antibody versions of the L19 antibody. We have performed a comparative biodistribution analysis in tumor-bearing mice, as well as an evaluation of pharmaceutical properties in vitro and in three different immunocompetent mouse models of cancer. One of the new products (termed L19L19-IL2) featured the L19 antibody in single-chain diabody format [36] and exhibited favorable properties in various types of functional analysis. L19L19-IL2 may thus represent a valuable alternative to L19-IL2 for future clinical development programs.

\section{RESULTS}

\section{Production and initial characterization of L19- IL2 and of four novel fusion proteins}

Eight novel immunocytokines comprising the variable heavy (VH) chain and variable light (VL) chain domains of the L19 antibody and an IL2 payload were generated. At first, four candidates bearing different linkers between the VH and VL were cloned. The L19IL2 immunocytokines were designed to comprise different linker sequences between the $\mathrm{VH}$ and $\mathrm{VL}$ domains in diabody format (neutral, positively charged and negatively charged). Subsequently, four more immunocytokines with novel formats were produced. These differed among each other for the spatial arrangement between the antigen binding fragment and the cytokine and, more importantly, for the number IL2 moieties (either one or two) (Figure 1A). All immunocytokines were characterized in vitro by SDS PAGE (Figure 1B) where a clean band was observable corresponding to the expected molecular weight. Production yields and characterization including of size exclusion chromatography, BIAcore and immunofluorescence are reported in Supplementary Figure 1. All the candidates showed only minor differences when characterized in vitro.

In vivo biodistribution studies were performed in F9 tumor-bearing mice using radioiodinated immunocytokine preparations. One immunocytokine format, composed by two L19 scFv domains in tandem diabody format linked to an IL2 payload at the C-terminus (named L19L19-IL2), had significantly superior tumor targeting properties, as reflected by the highest percentage of injected dose-per gram of the immunocytokine in the tumor, compared to the other tested formats (except for the GGSGG candidate where L19L19-IL2 had a higher accumulation but not significantly superior). Statistical analysis are reported in Supplementary Table 3A. Specifically, L19L19-IL2 showed an accumulation of about $7.7 \% \mathrm{ID} / \mathrm{g}$ in the tumor and a tumor-to-blood ratio of about 13 , while the other immunocytokines reached values of approximatively 5\% ID/g in the tumor (Figure 2, Supplementary Table 3B). However, it has to be considered that the biodistribution experiments evaluated the quantity of immunocytokine at the tumor site and not the quantity of IL2. In light of these results, we decided to further characterize the L19L19-IL2 format and benchmark it with our clinical grade L19-IL2 protein.

The monomeric nature of the new format could be an advantage in reducing the avidity effect of the regulatory $\mathrm{T}$ cells, thus reducing the inhibition of the antitumor response. We therefore compared the proliferation effect of the new monomeric L19L19-IL2 with the dimeric L19-IL2 on immune cell population of PBMCs.

Human PBMCs were isolated and incubated with different concentrations of the two candidates and 
a saline as reference for 5 days. Afterwards, cellular proliferation and $\mathrm{T}$ cells subpopulation were analyzed by FACS. A higher (but still comparable) percentage of FoxP3 $3^{+}$lymphocytes could be observed in PBMCs incubated with L19L19-IL2 at $10 \mathrm{nM}$ concentration. On the other hand, a lower percentage of $\mathrm{FoxP}^{+}$was notable in PBMCs incubated with the monomeric L19L19-IL2 at the lowest concentration (Figure 3). This result support the hypothesis that the new format might be less prone to stimulate regulatory $\mathrm{T}$ cells activity compared to the dimeric L19-IL2 at lower dose. There were no significant differences in the other subpopulation percentages.

\section{Comparative evaluation of the therapeutic properties of L19-IL2 and L19L19-IL2 in three different mouse models of cancer}

The in vivo performance of the new immunocytokine L19L19-IL2 was first evaluated in immunocompetent mice bearing subcutaneous CT26 colorectal carcinomas. The treatment started when the subcutaneously grafted tumors reached a size of approximatively $80 \mathrm{~mm}^{3}$. The new tandem diabody format was compared to the benchmark diabody format $[37,38]$ and to a saline. Immunocytokines were administered at equimolarity of IL2, meaning $50 \mu \mathrm{g}$ of L19-IL2 diabody and $82.5 \mu \mathrm{g}$ of L19L19-IL2 tandem diabody. Injections were done every second day for three times. L19-IL2 and L19L19-IL2 displayed comparable therapeutic activity, with the new format being slightly more effective in reducing the tumor growth (Figure 4). Body weight changes are reported in Supplementary Figure 4. Plasma collected 24 hours after the third injection showed that both immunocytokines successfully increased the level of plasmatic TNF- $\alpha$ and decreased the level of TGF- $\beta$. Moreover, a significant increase of interferon $\gamma$ in the plasma of mice treated with L19L19-IL2 was notable. Overall, the level of IL2 in the plasma was $<2 \mathrm{pg} / \mathrm{ml}$, confirming the good targeting

A

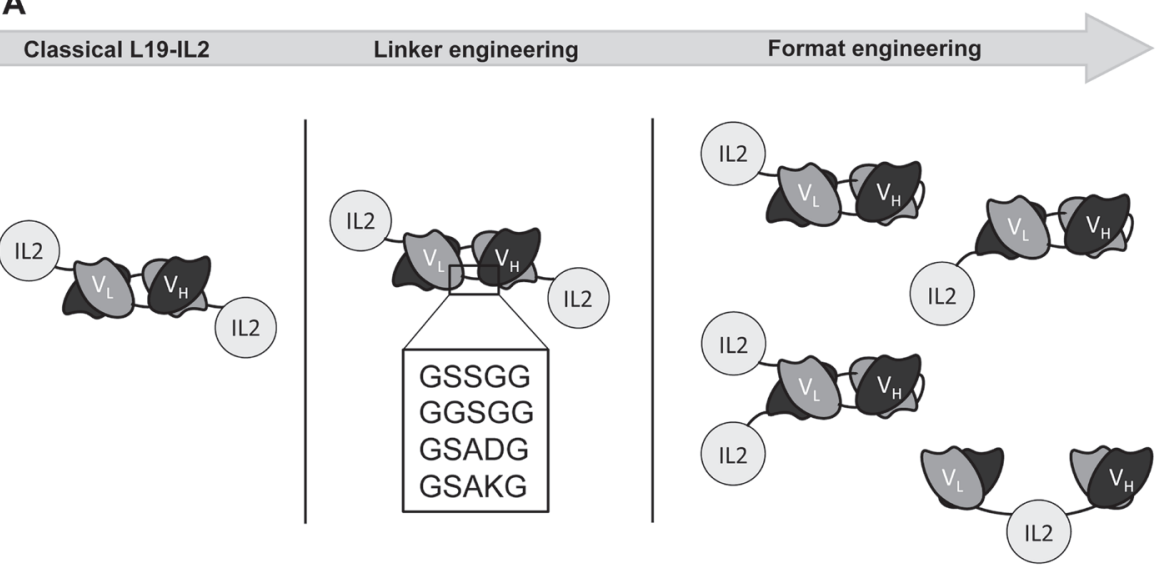

B
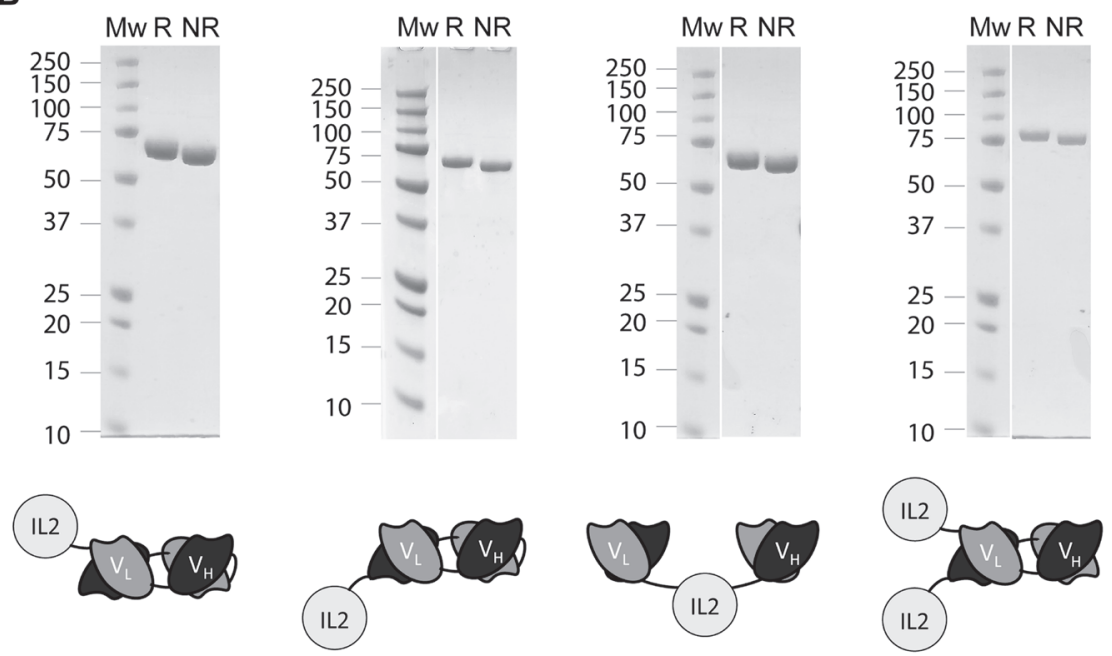

Figure 1: (A) Graphic representation of the all L19-IL2 fusion candidates comprising different VH-VL domain linker sequences (linker engineering), different arrangements between the IL2 and the L19 domains and different number of payloads (format engineering). (B) SDS-PAGE characterization of all explored formats. 
properties of the candidates (Supplementary Figure 2). Endotoxin level of the injected proteins was measured and resulted to be far below the recommended daily limit [39] (Supplementary Figure 3).

A second study was performed in a F9 teratocarcinoma model in $129 \mathrm{~Sv}$ mice. Exponentially growing tumor cells where injected in the right flank of the mice and treatment was started when tumors reached an average size of about $80 \mathrm{~mm}^{3}$. Since no significant toxicity was observed in the CT26 model, we chose to increase the dose to $100 \mu \mathrm{g}$ of L19-IL2 and $165 \mu \mathrm{g}$ of L19L19IL2. Both L19-IL2 and L19L19-IL2 showed therapeutic activity in slowing the tumor progression down, with the new format that achieved a stronger and longer lasting response (Figure 4). Better performances of L19L19IL2 could also be observed in the number of complete remissions: 3 for L19L19-IL2 compared to 2 for L19IL2. No significant changes in the serum cytokine were observed in this experiment (Supplementary Figure 2B).

A last in vivo experiment was conducted in WEHI-164 model in BALB/c mice. The WEHI-164 model had previously been reported to respond well to immune check point inhibitors, both as monotherapy and combination therapy [6]. Therefore, a treatment group with the combination of L19L19-IL2 and anti-PD-1 was included in this experiment. Exponentially growing WEHI-164 fibrosarcoma cells were injected in BALB/c mice and treatment started as tumors reached about $80 \mathrm{~mm}^{3}$ of average size. Also in this setting, L19L19-IL2 showed slightly better performances than L19IL2 in diabody format. Both formats displayed a potent tumor growth inhibition compared to the saline control and to the untargeted recombinant interleukin-2. As expected, the checkpoint inhibitor anti PD-1 showed a significant tumor growth retardation. The response obtained by administration of anti-PD-1 and L19L19-IL2, however, was not significantly better than the monotherapy with L19L19-IL2 in term of tumor growth inhibition (Figure 4). A durable response could be observed in 4 out of 5 mice treated with the combination. In these mice, no tumor growth could be observed up to 43 days after the therapy start.

To better understand the mechanism behind the anti-cancer response in the various treatment groups, we analyzed the $\mathrm{T}$ cells subpopulations in draining lymph nodes and in the tumors of treated WEHI-164 bearing mice. In total, four staining were performed to differentiate (i) $\mathrm{CD}^{+}, \mathrm{CD}^{+}, \mathrm{CD}^{+}$and $\mathrm{NK}$ cells, (ii) $\mathrm{CD} 44^{+}, \mathrm{CD} 2 \mathrm{~L}^{+}$, $\mathrm{CD}^{+}$and $\mathrm{AH}^{+}$cells, (iii) $\mathrm{CD}^{+}, \mathrm{CD}^{+}, \mathrm{PD}-1^{+}$and $\mathrm{TIM}^{+}$ cells and (iv) $\mathrm{CD}^{+}, \mathrm{FoxP}^{+}$cells. A significant increase in the percentage of $\mathrm{CD}^{+} \mathrm{T}$ cells could be observed both in the lymph nodes and in the tumors of the mice treated with L19-IL2, L19L19-IL2 and L19L19-IL2 in combination with anti-PD-1 but not in the mice treated with non-targeted recombinant IL2. Mice treated with anti-PD-1 alone showed a significant increase of $\mathrm{CD}^{+} \mathrm{T}$ cells only in the tumor. A decrease of $\mathrm{CD} 4^{+} \mathrm{PD}-1^{+}$cells in the lymph node of mice treated with L19L19-IL2 alone or in combination with anti-PD-1 could be observed. Importantly, there was a decreasing trend of $\mathrm{CD}^{+} \mathrm{FoxP}^{+}$ in the tumors of mice treated with L19L19-IL2 with antiPD-1 (Figure 5).

\section{DISCUSSION}

L19-IL2 is an immunocytokine featuring the L19 antibody fused to the cytokine IL2 payload, which is currently being investigated with encouraging results
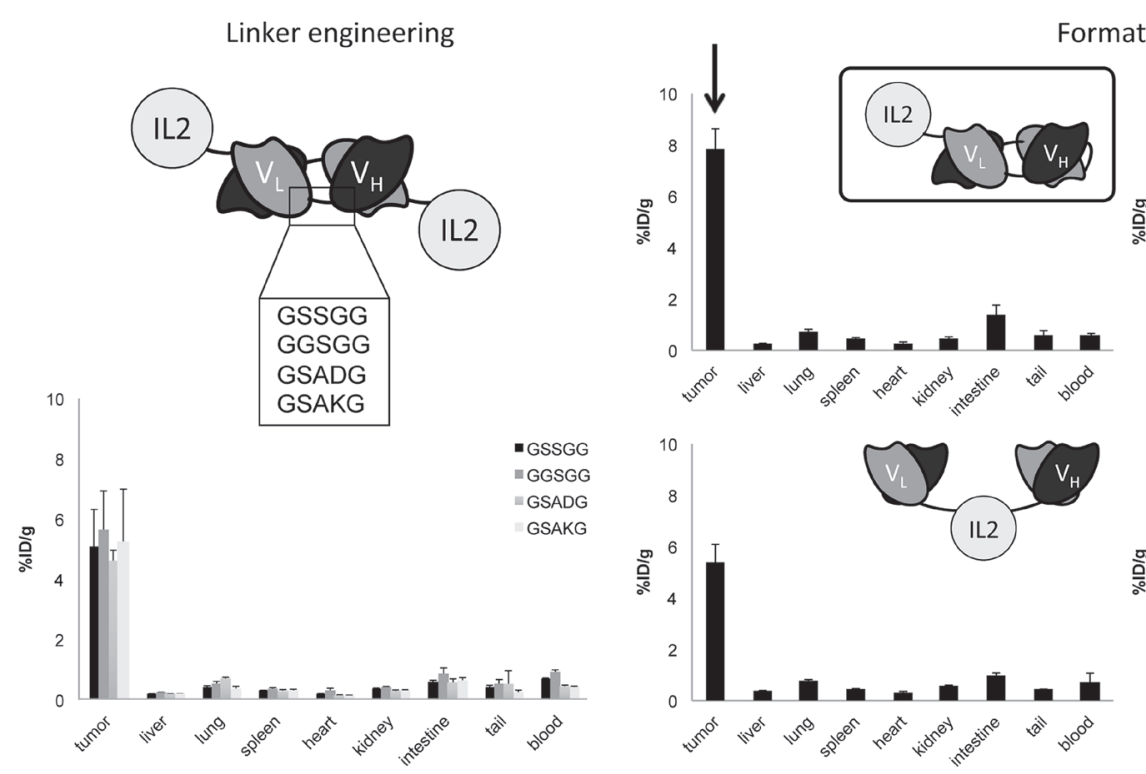

Format engineering
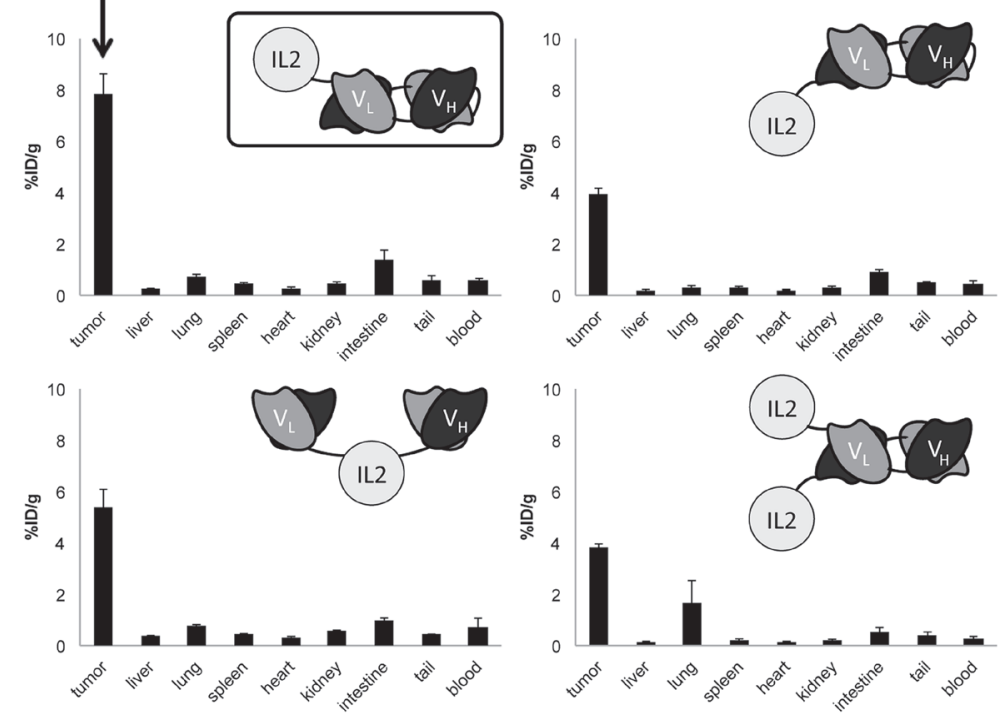

Figure 2: In vivo comparative quantitative biodistribution studies performed in immunocompetent mice bearing F9 teratocarcinoma tumors $(n=\mathbf{3}$ per group), using radioiodinated protein preparation. Data represent means of percentage of injected dose per gram $(\% \mathrm{ID} / \mathrm{g})$ values in tumor, blood and normal organs \pm SEM at 24 hours after intravenous injection. 
for the treatment of metastatic melanoma in phase II and phase III clinical trials, in combination with targeted TNF. In this study, we have investigated the therapeutic potential of four novel formats of immunocytokines based on the L19 antibody in single-chain diabody format and an IL2 payload.

In vitro characterization by multiple biochemical and immunological techniques showed that the various L19-IL2 fusion proteins were homogeneous and exhibited comparable binding properties. However, one of the newly developed formats (L19L19-IL2) showed an improved tumor uptake in quantitative biodistribution studies. In vitro, L19L19-IL2 showed a slightly decreased activation of regulatory $\mathrm{T}$ cells at low concentration and a higher percentage at $10 \mathrm{nM}$ concentration. This effect is compatible with the saturation of the IL2 receptor. It has been previously reported that opposite effects at low and high doses can be observed with cytokines [40, 41]. In vivo, both the conventional L19-IL2 format and the new L19L19-IL2 fusion protein revealed potent anticancer activity in three syngeneic mouse tumor models.

The observation that fusion proteins carrying two IL2 moieties may lead to a stronger stimulation of regulatory FoxP3 $^{+} \mathrm{T}$ cells is of potential biomedical relevance. On one hand, low dose IL2 has been proposed as treatment option for certain conditions like graft-versushost disease [42], systemic lupus erythematosus [43] and hepatitis C virus-induced vasculitis [44]. It is possible that the bivalent display of IL2 may lead to better therapeutics because of a higher binder avidity and improved $\mathrm{T}$ reg selectivity. On the other hand, it has been claimed that regulatory $\mathrm{T}$ cell activity may counteract cancer
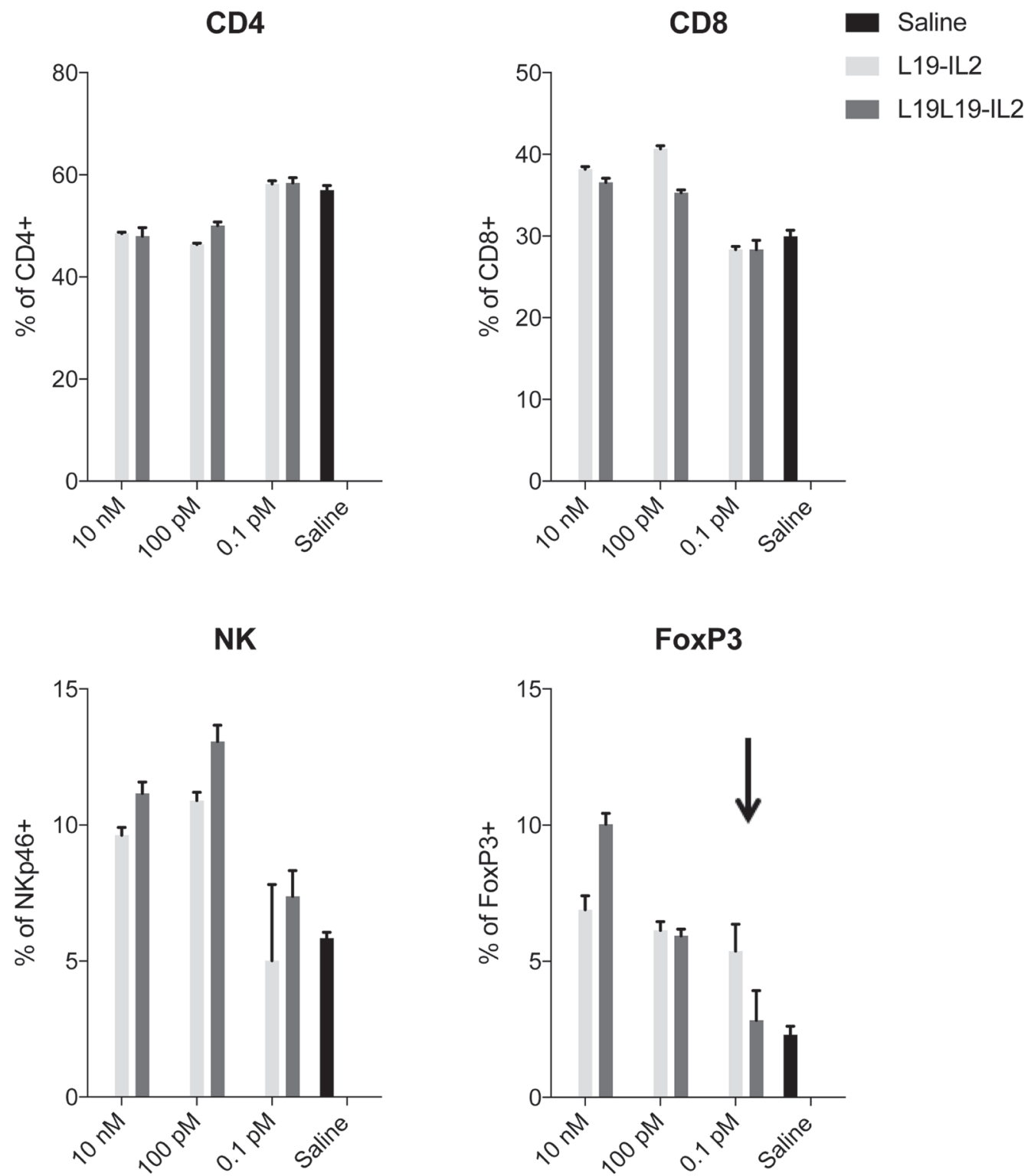

Figure 3: PBMCs proliferation assay. Expansion of $\mathrm{CD}^{+}, \mathrm{CD}^{+}, \mathrm{NKp} 46^{+}$and $\mathrm{FoxP}^{+}$cells was determined by antibody staining followed by flow cytometry analysis. Data represent means $\pm \operatorname{SEM},(n=3)$. 
immunotherapeutics [45] and, for this reason, L19L19IL2 may represent a promising monovalent alternative for anti-tumor development programs.

A durable complete regression in WEHI-164 tumor bearing mice was observed in mice treated with the combination of IL2 therapeutics with PD-1 blockade. Immune checkpoint inhibitors gained huge popularity due to their effectiveness in cancer therapy [4]. The use of IL2 with anti PD-1 is potentially a powerful combination strategy where IL2 stimulates natural killer cells and T lymphocytes and the PD-1 blockade hinders the immune cells exhaustion, which is typical of prolonged stimulation [46]. Recent studies have also described that engineered IL2 variants may well synergize with immune checkpoint inhibitors [47, 48]. The efficacy of this combination has been evaluated in clinical trials with encouraging results [NCT00058279, NCT01856023] [49, 50]. In immunocompetent $\mathrm{BALB} / \mathrm{c}$ mice, the tumor rejection process is dominated by $\mathrm{CD}^{+} \mathrm{T}$ cells which recognize $\mathrm{AH} 1$, a retroviral antigen selectively expressed in cancer [51].

Recombinant IL2 has shown encouraging results in the treatment of metastatic melanoma and renal cell carcinoma. Unfortunately, because of severe side effects, optimal therapeutic regimens could be achieved only for young and healthy patients [11]. The targeting of IL2 at the site of disease by means of antibodies as vehicles has been demonstrated to be an elegant solution to increase its therapeutic index in both in pre-clinical [23, 24, 37] and in clinical research. In our study, we could observe a striking difference in the tumor growth retardation between mice treated with untargeted and mice treated with targeted IL2, where the last managed to achieve a stronger and prolonged effect.

L19-IL2 has been administered to more than 200 patients with different types of malignancies [52, 53]. The most advanced clinical studies include its use in combination with L19-TNF for the treatment of fully resectable stage IIIB, C melanoma [NCT02938299] and in combination with stereotactic ablative radiotherapy for the treatment of oligometastatic tumors [NCT03705403]. It is likely that the substitution of L19-IL2 with L19L19-IL2, ideally in combination with PD-1 blockade, may lead to a further increase of therapeutic activity. Phase II studies with L19-IL2 in patients with metastatic melanoma had shown that some patients enjoyed major durable responses with favorable safety profile $[53,54]$ but more than $50 \%$ of the subjects did not achieve a partial response. The use of improved molecular formats and of judiciously chosen combination partners will further expand the applicability

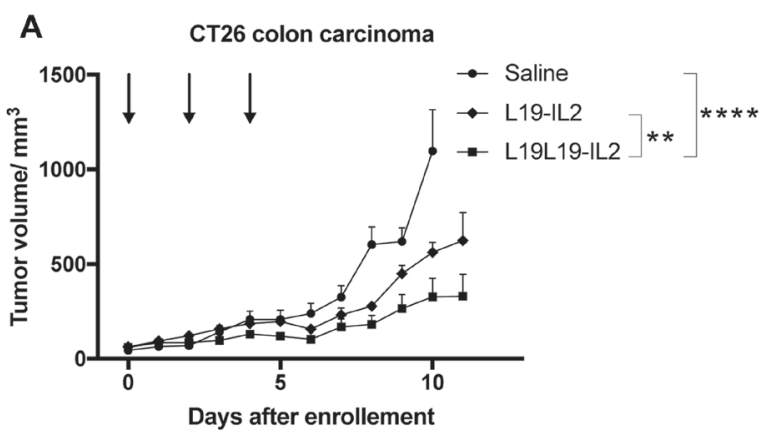

C

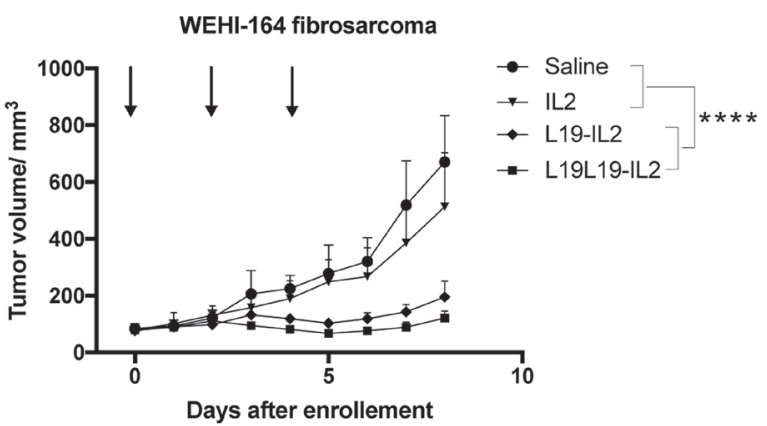

B F9 teratocarcinoma

D
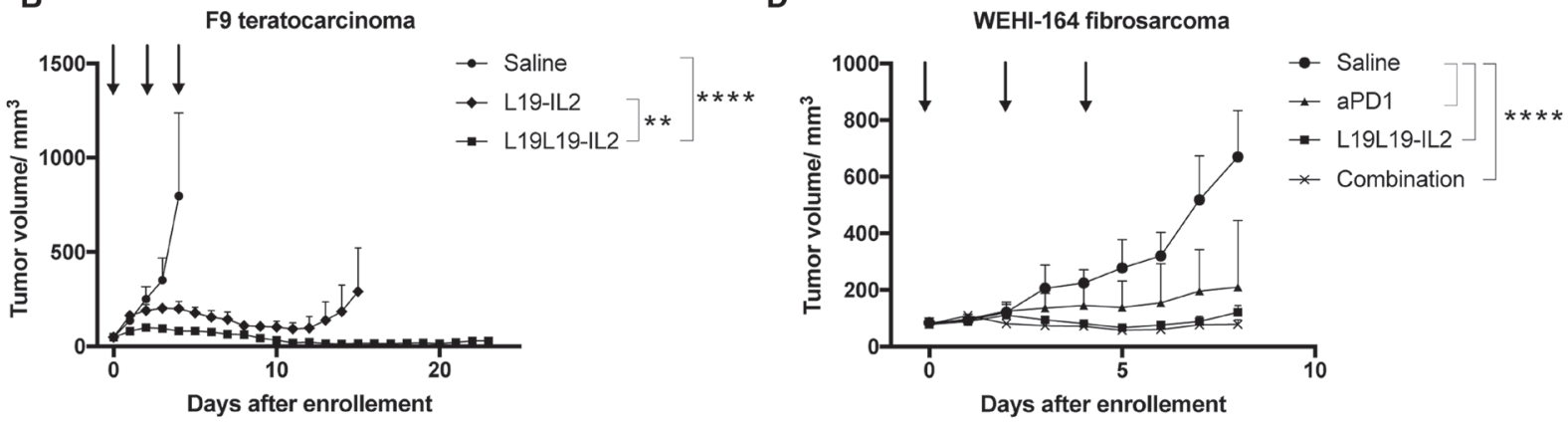

Figure 4: Tumor therapy experiments in immune competent mice. Treatments started when tumors reached a size of approximatively $80 \mathrm{~mm}^{3}$. Fusion proteins were administered every second day for three times. (A) Therapy with L19-IL2 and L19L19IL2 in BALB/c mice bearing CT26 colon carcinoma tumors. The fusion proteins were administered at $50 \mu \mathrm{g}$ and $82.5 \mu \mathrm{g}$ in order to have equimolarity. (B) Therapy with L19-IL2 and L19L19-IL2 in 129/ScEv mice bearing F9 teratocarcinoma tumors. $100 \mu \mathrm{g}$ of L19-IL2 and $165 \mu \mathrm{g}$ of L19L19-IL2 were administered. (C) Therapy in BALB/c mice bearing WEHI-164 fibrosarcoma with therapeutic proteins administered as single agents. $40 \mu \mathrm{g}$ of recombinant IL2, $100 \mu \mathrm{g}$ of L19-IL2 and $165 \mu \mathrm{g}$ of L19L19-IL2 were injected. (D) The same setting was evaluated in combination with the anti-PD-1 checkpoint inhibitor. $200 \mu \mathrm{g}$ of anti-PD-1, $165 \mu \mathrm{g}$ of L19L19-IL2 and a combination of the two were administered. Statistical significances were determined with a regular two-way ANOVA test with Bonferroni post-test correction. Data represent means \pm SEM. ${ }^{*}=p<0.05,{ }^{* *}=p<0.01,{ }^{* * * *}=p<0.0001$. 
and performance of IL2 therapeutics. L19L19-IL2 could represent a promising monovalent alternative to L19-IL2, which deserves to be clinically investigated, because of its favorable tumor homing properties and reduced activation of regulatory $\mathrm{T}$ cells.

\section{MATERIALS AND METHODS}

\section{Cloning}

\section{Cloning of the L19 diabody-IL2 conjugate with a GSSGG VH-VL domain linker sequence}

Firstly, the DNA fragment encoding the L19 diabody comprising the GSSGG VH-VL domain linker sequence was cloned by PCR-amplification of the L19 gene (Supplementary Table 1A). The used PCR primers are reported in the Supplementary Table 2A. For the L19 PCR, primers HindIIISIP and L19Linker were used. The DNA sequence encoding the IL2 was cloned from the IL2 gene (Supplementary Table 1B) using primers LinkerIL2 and IL2stopNot $<$. The two DNA fragments (L19 antibody and IL2) were assembled by means of PCR, amplified using primers HindIIISIP and IL2stopNotI, double digested with HindIII/NotI and cloned into a pcDNA 3.1 $(+)$ vector.

\section{Cloning of L19 diabody-IL2 conjugates with different VH-VL domain linker sequences}

Three further diabody-IL2 conjugates were prepared by inserting linker sequences GGSGG, GSADG and GSAKG between the heavy and light chain variable

\section{A CD4}

dLN

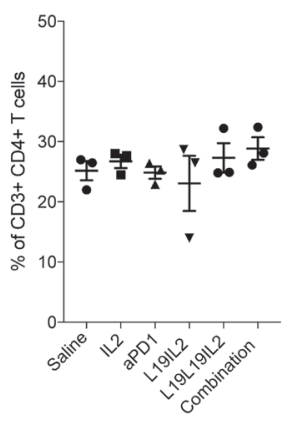

Tumor

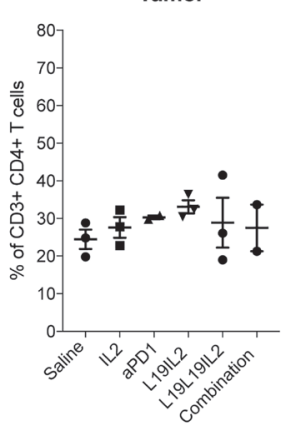

CD8

dLN
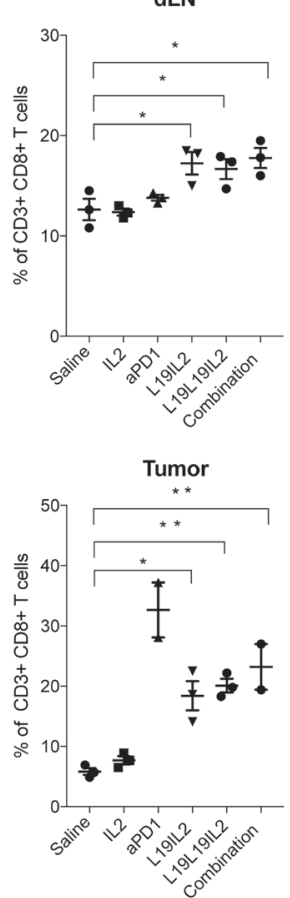

FoxP3
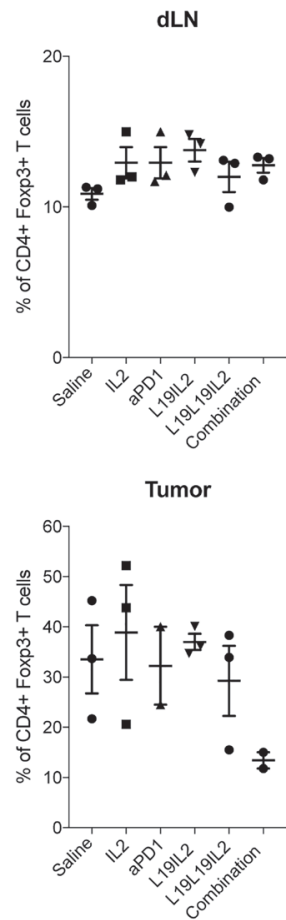

B
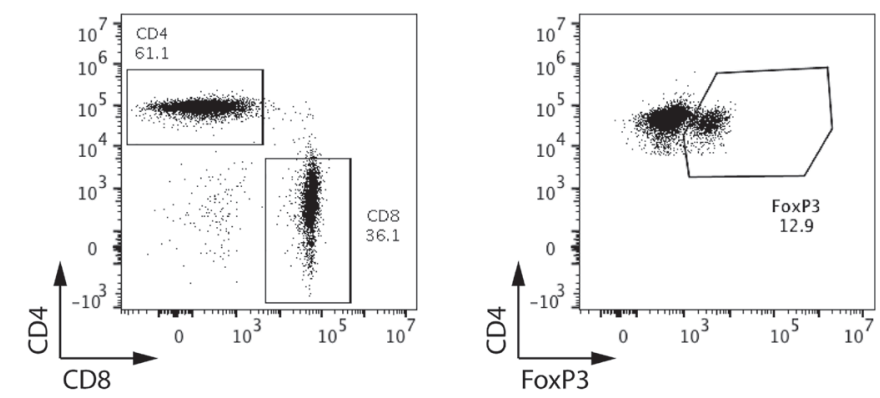

Figure 5: (A) Immunophenotypic analysis of lymphocyte in tumor and in tumor draining lymph node (dLN) of treated mice. Individual plots show the percentage of $\mathrm{CD} 4^{+} \mathrm{T}$ cells, $\mathrm{CD} 8^{+} \mathrm{T}$ cells and $\mathrm{CD} 4^{+} \mathrm{FoxP} 3^{+} \mathrm{T}$ cells in draining lymph nodes on mice from the different therapy groups $(n=2-3)$. Statistical significances were determined with a regular one-way ANOVA test with Bonferroni post-test correction. Data represent means \pm SEM. ${ }^{*}=p<0.05,{ }^{* *}=p<0.01$. (B) Representative FACS plots of CD4 ${ }^{+} \mathrm{T}$ cell, $\mathrm{CD}^{+} \mathrm{T}$ cell (left) and CD4 ${ }^{+}$FoxP3 ${ }^{+} \mathrm{T}$ cell subsets (right). 
domains of the L19 diabody-IL2 conjugate. The L19 diabody-IL2 conjugates were prepared by means of PCR assembly of a fragment "A" (encoding the L19 heavy chain variable domain), and a fragment "B" (encoding the L19 light chain variable domain and the IL2 payload). Fragments " $\mathrm{A}$ " and "B" were amplified from the L19 diabody-IL2 molecule comprising the GSSGG VH-VL domain linker using the primers listed in the Supplementary Table 2B.

The "A" and " $\mathrm{B}$ " fragments were then PCRassembled, PCR-amplified and double digested with HindIII/NotI-HF and cloned into the double digested vector pcDNA $3.1(+)$.

The resulting plasmids were amplified and used for cell transfection.

\section{Cloning of the single-chain diabody C-terminal fusion protein (L19L19-IL2)}

All the primers used for the cloning of the new formats of L19-IL2 are reported in the Supplementary Table 2C.

The C-terminal fusion protein (L19L19-IL2) coding sequence was generated using L19-IL2 as template.

The L19 gene was PCR amplified using primers LnkDP47 $>$ and L19G4S3 $<$. The IL2 gene was amplified using primers G4S3IL2 $>$ and IL2StopNot $<$. The two intermediate fragments were PCR-assembled, PCRamplified using primers HindLnk $>$ and IL2StopNot $<$, double digested with HindIII/NotI-HF and cloned into a pcDNA $3.1(+)$ vector (resulting into a pcDNA 3.1 vector containing the sequence HindIII (restriction site)-L19-IL2NotI (restriction site)).

A second L19 gene was PCR amplified using primers NheLead $>$ and L19Hind $<$, double digested by NheI/HindIII and inserted into the previously generated pcDNA $3.1(+)$ vector containing the sequence HindIII (restriction site)-L19-IL2-NotI (restriction site), resulting into the full length L19L19-IL2.

The resulting plasmids were amplified and used for cell transfection.

\section{Cloning of the single-chain diabody $\mathbf{N}$-terminal fusion protein (IL2-L19L19)}

The N-terminal fusion protein (IL2-L19L19) coding sequence has been generated using L19-IL2 as template.

The IL2 gene was amplified using primers LeadIL2> and $\mathrm{IL} 2 \mathrm{G} 4 \mathrm{~S} 3<$. The L19 gene was PCR amplified from G4S3L19> and L19Hind $<$. The two intermediate fragments were PCR-assembled, PCR-amplified using primers NheLead $>$ and L19Hind $<$, double digested with NheI/HindIII and cloned into a pcDNA $3.1(+)$ vector (resulting into a pcDNA $3.1(+)$ vector containing the sequence NheI (restriction site)-IL2-L19-HindIII (restriction site)).

A second L19 gene was PCR amplified a first time using primers LnkDP47> and L19StopNot $<$ and a second time using primers HindLnk $>$ and L19StopNot $<$.
The DNA fragment was subsequently double digested using HindIII/Not-HF and inserted into the previously generated pcDNA $3.1(+)$ vector containing the sequence NheI (restriction site)-IL2-L19-HindIII (restriction site), resulting in the full length IL2-L19L19.

The resulting plasmids were amplified and used for cell transfection.

Cloning of the L19 single-chain diabody with IL2 conjugated to its C- and N-termini (IL2-L19L19-IL2)

The IL2-L19L19-IL2 coding sequence was generated using the previously cloned L19L19-IL2 and IL2-L19L19 as starting material.

The vector pcDNA $3.1(+)$ containing the sequence NheI (restriction site)-IL2-L19-HindIII (restriction site)-L19 was digested by NheI/HindIII in order to obtain the IL2-L19 DNA fragment. At the same time, the vector pcDNA $3.1(+)$ containing the sequence NheI (restriction site)-L19- HindIII (restriction site)-L19-IL2 was digested by NheI/HindIII, in order to remove the first L19 moiety and replace it with NheI (restriction site)-IL2-L19-HindIII (restriction site). By doing so, the full length IL2-L19L19IL2 was obtained.

Cloning of IL2 conjugated at its C-terminus and at its $\mathrm{N}$-terminus to two single-chain diabodies ("Crab")

The "Crab" immunocytokine L19-IL2-L19 coding sequence was generated using L19-IL2 as template.

A first DNA fragment was amplified using primers HindLead $>$ and DP47G4S2.5<. A second DNA fragment was amplified using primers G4S2.5VL $>$ and IL2G4S3Bam $<$. The two intermediate fragments were PCR-assembled, PCR-amplified using primers HindLead $>$ and IL2G4S3Bam<, double digested with HindIII/BamHI and cloned into a pcDNA $3.1(+)$ vector (resulting in the vector pcDNA $3.1(+)$ containing HindIII (restriction site)L19-IL2-BamHI (restriction site)).

A third DNA fragment was amplified using primers BamG4S3L19> and DP47G4S2.5<. A fourth DNA fragment was amplified using primers G4S2.5VL $>$ and L19StopNot $<$. The two intermediate fragments were PCRassembled, PCR-amplified using primers BamG4S3L19> and L19StopNot<, double digested with BamHI/NotI $\mathrm{HF}$ and cloned into the previously generated pcDNA 3.1 $(+)$ vector containing the sequence HindIII (restriction site)-L19-IL2-BamHI (restriction site), resulting in the full length L19-IL2-L19 "Crab" molecule. The resulting plasmids were amplified and used for cell transfection.

\section{Expression and purification of L19-IL2 immunocytokines}

\section{Cell culture and transfection}

Transfected CHO-S cells (Chinese Hamster Ovary; Invitrogen) were cultured in suspension in PowerCHO-2CD medium (Lonza), supplemented with 
Ultraglutamine-1 (Lonza), HT-supplement (Gibco) and an antibiotic-antimycotic (Gibco).

F9 teratocarcinoma cells, CT26 colon carcinoma cells and WEHI-164 fibrosarcoma cells (ATCC) were grown according to supplier's protocol and kept in culture for no longer than 3 weeks. F9 cells were expanded and cultured in DMEM medium (Gibco) supplemented with $10 \%$ of fetal bovine serum and antibiotic-antimycotic (Gibco) while CT26 and WEHI-164 were expanded and cultured in RPMI1640 medium (Gibco) supplemented with $10 \%$ fetal bovine serum and antibiotic-antimycotic (Gibco).

\section{Expression and purification of L19-IL2 immunocytokines}

The different L19-IL2 candidates were expressed using transient gene expression in CHO-S cells. For $1 \mathrm{~mL}$ of production $4 \times 10^{6} \mathrm{CHO}-\mathrm{S}$ cells in suspension were centrifuged and resuspended in $1 \mathrm{~mL}$ ProCHO4 medium (Lonza). $0.625 \mu \mathrm{g}$ of plasmid DNAs followed by $2.5 \mu \mathrm{g}$ polyethylene imine (PEI; $1 \mathrm{mg} / \mathrm{mL}$ solution in water at $\mathrm{pH}$ 7.0) per million cells were then added to the cells and gently mixed. The transfected cell cultures were incubated in a shaker incubator at $31^{\circ} \mathrm{C}$ for 6 days. The suspensions were then centrifuged at $4^{\circ} \mathrm{C} 4900 \mathrm{rpm}$ for $30 \mathrm{~min}$. Supernatant was harvested and filter by Nalgene Rapid-Flow Bottle Top Filter (Nalgene) and incubated for $2 \mathrm{~h}$ at room temperature and shaking conditions with protein A Sepharose. The resin was then loaded in a column support and thereafter washed with $200 \mathrm{~mL}$ of Buffer A (100 mM NaCl, $0.5 \mathrm{mM}$ EDTA, $0.1 \%$ Tween 20 in PBS) and then with $200 \mathrm{~mL}$ of Buffer B (500 mM NaCl, $0.5 \mathrm{mM}$ EDTA in PBS). The antibody product was eluted using 10-15 $\mathrm{mL}$ Glycine $100 \mathrm{mM}$ and fractions of $1 \mathrm{~mL}$ were collected. OD at an absorbance of $280 \mathrm{~nm}$ (OD280) was measured and fractions containing protein $(\mathrm{OD} 280>0.1 \mathrm{mg} / \mathrm{mL})$ were pooled and loaded on SpectraPor dialysis membrane Mw 25,000 (Spectrum laboratories) and dialyzed in PBS o/n at $4^{\circ} \mathrm{C}$.

\section{Characterization of the L19-IL2 immunocytokines}

\section{SDS-PAGE and size-exclusion chromatography}

The purified immunocytokines were characterized by SDS-PAGE and size-exclusion chromatography. SDS-PAGE was performed with $10 \%$ gels (NP0302BOX, Invitrogen) under reducing and non-reducing conditions. Purified clones were analyzed by size-exclusion chromatography on a Superdex 200 increase 10/300 GL column on an ÄKTA FPLC (GE Healthcare, Amersham Biosciences).

\section{Affinity measurements}

Affinity measurements were performed by surface plasmon resonance using a BIAcore $\times 100$ instrument (BIAcore, GE Healtchare) using a fibronectin 7B89 domain coated CM5 chip. Samples were injected as serialdilutions, in a concentration range from $1 \mathrm{mM}$ to $250 \mathrm{nM}$.
Regeneration of the chip was performed using $10 \mathrm{mM}$ $\mathrm{HCl}$.

\section{PBMCs proliferation assay}

PBMCs were isolated from healthy donor by density gradient using Ficoll-Paque (GE Healthcare, 17-544-02). Briefly, $50 \mathrm{ml}$ of blood were collected in Heparin tubes. Blood was diluted 1:1 with PBS pH 7.4, 2 mM EDTA and slowly added to $19 \mathrm{ml}$ of Ficoll solution. Samples were centrifuged at $400 \mathrm{~g}$ for 40 minutes at room temperature with low acceleration and deceleration. Buffy-Coat was collected, washed with PBS pH 7.4, 2 mM EDTA and resuspended in X-Vivo 15 medium.

$5 \times 10^{4}$ PBMCs where incubated for 5 days at $37^{\circ} \mathrm{C}$ with either $10 \mathrm{nM}, 100 \mathrm{pM}$ or $0.1 \mathrm{pM}$ of the fusion proteins L19-IL2 or L19L19-IL2 and saline solution as negative control. All the groups were done in triplicates. The fifth day, proliferation and $\mathrm{T}$ cells subpopulations were determined by flow cytometry. Fluorophoreconjugated antibodies against CD3 (clone HIT3a), CD4 (clone A161A1), CD8 (clone SK1), NKp46 (clone 9E2) and FoxP3 (clone 206D), as well as Zombie Red viability dye were all purchased from BioLegend.

PBMCs cells suspension were washed in PBS and incubated with the staining reagents. Zombie Red dye diluted 1:500 in PBS was used to stain cells (15' minutes at room temperature) followed by staining with antibodies in PBS containing $0.5 \%$ BSA and 2 mM EDTA for $30^{\prime}$ at $4^{\circ} \mathrm{C}$.

For the staining of intracellular markers with antibodies against FoxP3, cells were fixed and permeabilized using eBioscience ${ }^{\mathrm{TM}}$ Foxp3/Transcription Factor Staining Buffer Set (Thermofisher), according to the supplier's protocol.

Samples were analysed by CytoFLEX S (Beckman Coulter) and data were processed using FlowJo software (FlowJo, LLC, version 10).

Data were analyzed using Prism 7.0 (GraphPad Software, Inc.). Statistical significances data were determined with a regular one-way ANOVA test with Bonferroni post-test correction. Data represent means \pm SEM. $P<0.05$ was considered statistically significant. ${ }^{*}=$ $p<0.05,{ }^{* *}=p<0.01$.

\section{Immunofluorescence and biodistribution experiments}

\section{Animal studies}

All animal experiments were conducted in accordance with Swiss animal welfare laws and regulations under the license number 27/2015 and 04/2018 granted by the Veterinäramt des Kantons Zürich.

\section{Tumor implantation}

The murine F9 teratocarcinoma tumor cell line was used to generate the syngeneic tumor model. F9 cells were 
cultured on $0.1 \%$ gelatin-coated tissue culture flasks in DMEM medium supplemented with $10 \%$ FCS. F9 tumor cells $\left(25 \times 10^{6}\right.$ cells resuspended in $150 \mu \mathrm{L}$ of HBSS buffer) were then implanted subcutaneously in the right flank of $129 / \mathrm{Sv}$ mice (females, six to eight weeks-old).

\section{Biodistribution studies}

The L19-IL2 immunocytokines $(100 \mu \mathrm{g})$ were radioiodinated with $125 \mathrm{I}$ and Chloramine $\mathrm{T}$ hydrate and purified on a PD10 column. Radiolabeled immunocytokines were injected into the lateral tail vein of immunocompetent (129/Sv) mice bearing subcutaneously implanted F9 murine teratocarcinomas. The injected dose per mouse varied between 12 and $15 \mu \mathrm{g}$. Mice were sacrificed 24 hours after injection. Organ samples were weighted and radioactivity was counted using a Packard Cobra gamma counter. The protein uptake in the different organs was calculated and expressed as the percentage of the injected dose per gram of tissue $(\% \mathrm{ID} / \mathrm{g})$. Data were analyzed using Prism 7.0 (GraphPad Software, Inc.). Statistical significances data were determined with a regular one-way ANOVA test with Bonferroni post-test correction. Data represent means \pm SEM. $P<0.05$ was considered statistically significant. ${ }^{*}=p$ $<0.05,{ }^{* *}=p<0.01,{ }^{* * *}=p<0.001$.

\section{Immunofluorescence experiments}

Immunofluorescence was performed on frozen murine F9 teratocarcinoma sections $(8 \mu \mathrm{m})$. The tumor sections were fixed using ice-cold acetone $(5 \mathrm{~min})$ and blocked with $20 \%$ fetal bovine serum in PBS for $45 \mathrm{~min}$. The L19-IL2 immunocytokines were added to the tumor sections at a concentration of $5 \mu \mathrm{g} / \mathrm{mL}$ in a $2 \% \mathrm{BSA} / \mathrm{PBS}$ solution and incubated for $1 \mathrm{~h}$ at room temperature. Antihuman interleukin-2 (final dilution 1:150) (eBioscience, 14-7029-85) was used as the secondary antibody to detect the L19-IL2 immunocytokines. The secondary antibody was added to the tumor sections in a $2 \% \mathrm{BSA} /$ PBS solution and incubated at room temperature for $1 \mathrm{~h}$. Donkey anti-rat Alexa 488 antibody (final dilution 1:500) (Invitrogen, A21208) was used as the tertiary antibody. Nuclei were counterstained with DAPI. Slides were analyzed with an Axioskop2 mot plus microscope.

\section{Therapy studies in CT26 colon carcinoma, F9 teratocarcinoma and WEHI-164 fibrosarcoma models}

\section{Therapy in CT26}

Six to eight-weeks-old female BALB/c mice were purchased from Janvier. After one week of acclimatization, mice were injected with $30 \times 10^{6}$ exponentially growing CT26 cells subcutaneously in the right flank. Mice were monitored daily, tumor volume was measured with a caliper and the volume was calculated as follows: (length $[\mathrm{mm}] \times$ width $\left.[\mathrm{mm}]^{2}\right) / 2$. When tumors reached a suitable size $\left(70-100 \mathrm{~mm}^{3}\right)$, mice were randomized and injected three times, every 48 hours, into the lateral tail vein with either the immunocytokines (50 $\mu \mathrm{g}$ L19-IL2, $82.5 \mu \mathrm{g}$ L19L19-IL2) or the saline solution as negative control. Euthanization was performed when the tumor volume reached more than $1500 \mathrm{~mm}^{3}$, weight loss exceeded $15 \%$, tumors were ulcerated or 24 hours after every protein injection for infiltrate and cytokine plasma level analysis. Results are expressed as tumor volume in $\mathrm{mm}^{3}+/-$ SEM. 5 mice per group were used.

\section{Therapy in F9}

Six to eight-weeks-old female $129 / \mathrm{Sv}$ mice were purchased from Janvier. After 1 week of acclimatization, $6 \times 10^{6}$ exponentially growing F9 teratocarcinoma cells were implanted subcutaneously in the right flank of the mice. Mice were monitored daily, tumor volume was measured with a caliper and the volume was calculated as follows: (length $[\mathrm{mm}] \times$ width $\left.[\mathrm{mm}]^{2}\right) / 2$. When tumors reached a suitable size $\left(70-100 \mathrm{~mm}^{3}\right)$, mice were randomized and injected three times, every 48 hours, into the lateral tail vein with either the immunocytokines (100 $\mu \mathrm{g}$ L19-IL2, $165 \mu \mathrm{g}$ L19L19-IL2) or the saline solution as negative control. Euthanization was performed when the tumor volume reached more than $1500 \mathrm{~mm}^{3}$, weight loss exceeded $15 \%$, tumors were ulcerated or 24 hours after every protein injection for infiltrate and cytokine plasma level analysis. Complete remissions were observed until 35 days after therapy start. Results are expressed as tumor volume in $\mathrm{mm}^{3}+/-$ SEM. 5 mice per group were used.

\section{Therapy in WEHI-164}

Six to eight-weeks-old female BALB/c mice were purchased from Janvier. After one week of acclimatization, mice were injected with $3 \times 10^{6}$ exponentially growing WEHI-164 cells subcutaneously in the right flank. Mice were monitored daily, tumor volume was measured with a caliper and the volume was calculated as follows: (length $[\mathrm{mm}] \times$ width $\left.[\mathrm{mm}]^{2}\right) / 2$. When tumors reached a suitable size (about $80 \mathrm{~mm}^{3}$ ), mice were randomized and injected three times, every 48 hours, into the lateral tail vein with either the immunocytokines $(100 \mu \mathrm{g}$ L19IL2, $165 \mu \mathrm{g}$ L19L19-IL2), the recombinant human IL2 $(40 \mu \mathrm{g})$, the anti-PD-1 (clone J43; BioXCell) $(200 \mu \mathrm{g})$, the combination of L19L19-IL2 and anti-PD-1 (165 $\mu \mathrm{g}$ $+200 \mu \mathrm{g}$ ) or the saline solution as negative control. Euthanization was performed when the tumor volume reached more than $1500 \mathrm{~mm}^{3}$, weight loss exceeded $15 \%$, tumors were ulcerated or 24 hours after the last protein injection for infiltrate and cytokine plasma level analysis. Complete remissions were observed until 43 days after therapy start. Results are expressed as tumor volume in $\mathrm{mm}^{3}+/-$ SEM. 5 mice per group were used.

\section{Cytokine analysis}

For the cytokine level analysis, mice were injected according to the therapy schedule and blood was collected 
24 hours after the first, second and third immunocytokine injection cycle. Blood was collected rapidly into heparin coated tubes (BD Microtainer, 365966), centrifuged for 10 minutes at $4^{\circ} \mathrm{C}$ and plasma was collected and stored at $-80^{\circ} \mathrm{C}$. Samples were sent to Cytolab (Regensdorf) for cytokine plasma level analysis.

\section{Analysis of immune infiltrates}

Fluorophore-conjugated antibodies against CD3 (clone 17A2), CD4 (clone GK1.5), CD8 (clone 53-6.7), NK1.1 (clone PK136), I-A/I-E (clone M5/114.15.2), CD62L (clone MEL-14), CD44 (clone IM7), PD-1 (clone RMP1-30), TIM3 (clone RMT3-23) and FoxP3 (clone MF-14) and Zombie Red viability dies were all purchased from BioLegend. AH1-loaded, PE-conjugated H-2 $\mathrm{L}^{\mathrm{d}}$ tetramers were obtained as previously described [51].

Tumors, right axillary and right inguinal tumordraining lymph nodes of mice bearing WEHI-164 fibrosarcoma were collected between 48 and 72 hours after the last injection of fusion proteins or the saline. Tumors were chopped into small pieces and incubated in an orbital shaker at $37^{\circ} \mathrm{C}$ for $30^{\prime}$ in RPMI-1640 medium containing $1 \times$ Antibiotic-Antimycotic (Thermofisher, 15240062), $1 \mathrm{mg} / \mathrm{mL}$ Collagenase II (Thermofisher, 17101015) and $0.1 \mathrm{mg} / \mathrm{mL}$ DNAse I (Roche, 10104159001). The resulting cells suspensions were filtered through a $70 \mu \mathrm{m}$ cell strainer (Corning) and treated with Red Blood Cells Lysis buffer (Biolegend, 420301) following supplier's recommendations. Lymph nodes were smashed on a $70 \mu \mathrm{m}$ cell strainer (Corning).

Tumor and lymph nodes cells suspension were washed in PBS and incubated with the staining reagents. Zombie Red dye diluted 1:500 in PBS was used to stain cells (15' minutes at room temperature) followed by staining with antibodies and tetramers in PBS containing $0.5 \%$ BSA and $2 \mathrm{mM}$ EDTA for $30^{\prime}$ at $4^{\circ} \mathrm{C}$.

For the staining of intracellular markers by means of antibodies against FoxP3, cells were fixed and permeabilized using eBioscience ${ }^{\mathrm{TM}}$ Foxp3/Transcription Factor Staining Buffer Set (Thermofisher), according to the supplier's protocol.

Samples were analysed by CytoFLEX S (Beckman Coulter) and data were processed using FlowJo software (FlowJo, LLC, version 10). The total number of living cells in the tumor was calculated by detracting dead cells and debris by the total number of recorded events.

Data were analyzed using Prism 7.0 (GraphPad Software, Inc.). Statistical significances were determined with a regular one-way ANOVA test with Bonferroni posttest correction. Data represent means \pm SEM. $P<0.05$ was considered statistically significant. ${ }^{*}=p<0.05,{ }^{* *}=p<0.01$.

\section{Abbreviations}

Amp: Ampicillin; Bp: Base pair; BSA: Bovin serum albumin; CDR: Complementarity determining region;
$\mathrm{C}_{\mathrm{H}}$ : Constant domain of antibody heavy chain; $\mathrm{CHO}$ : Chines hamster ovary; $\mathrm{C}_{\mathrm{L}}$ : Constant domain of antibody light chain; CV: Column volume; DAPI: 4',6-diamidin2-fenilindolo; DMEM: Dulbecco's Modified Eagle Medium; dNTP: Deoxynucleotides (dATP, dCTP, dGTP, dTTP); DNA: Deoxyribonucleic acid; E. coli: Escherichia coli; EDA: Extra domain A; EDB: Extra domain B; EDTA: Ethylene diamine immunoabsorbent assay; ELISA: Enzyme-linked immunosorbent assay; FACS: Fluorescence-activated cell sorting; FBS: Fetal bovin serum; FCS: Fetal calf serum; FPLC: Fast protein liquid chromatography; HRP: Horseradish peroxidase; Glu: Glucose; ID/g: Injected dose per gram; IL2: Interleukin 2; Ig: Immunoglobulin; $\mathrm{K}_{\mathrm{D}}$ : Dissociation constant; kDa: Kilo Dalton; LB: Loading buffer; mAb: Monoclonal antibody; M: Mol/l; MES: 2-(N-morpholino)ethanesulfonic acid Buffer; MOPS: 3-(N-morpholino)propansulfonic acid Buffer; MPBS: Skimmed milk powder in PBS; Mw: Molecular weight; OD: Optical density; PBMC: Peripheral blood mononuclear cell; PBS: Phosphate buffer saline; PCR: Polymerase chain reaction; PD-1: Programmed cell death protein 1; PD-L1: Programmed death-ligand 1; PEG Polyethilene glycol; PEI: Polyethileneimine; pI: Isoelectric point; Rpm: Revolutions per minute; RPMI: Roswell Park Memorial Institute; RT: Room temperature (20-24 $\left.{ }^{\circ} \mathrm{C}\right)$; RU: Resonance units; scFv: Single chain variable fragments; SDS-PAGE: Sodium dodecylsulfatepolyacrilamide gel electrophoresis; SEM: Standard error of the mean; SPR: Surface plasmon resonance; $\mathrm{T}_{1 / 2}$ : Half-life; TBE: Tris/Borate/EDTA buffer; TEA: Triethylamin; TGE: Transient gene expression; TIM: T-cell immunoglobulin and mucin domain 1; TNF Tumor necrosis factor; Tris: Tris (hydroxymethyl)aminomethane; $\mathrm{V}_{\mathrm{H}}$ : Variable domain of antibody heavy chain; $\mathrm{V}_{\mathrm{L}}$ : Variable domain of antibody light chain.

\section{Author contributions}

T.O. and A.V designed research. T.O., B.G., M.S. and R.C. performed research. T.O., A.V. and D.N. wrote the paper.

\section{ACKNOWLEDGMENTS}

We thank Charlotte Howels, Samuele Cazzamalli and Roberto De Luca for their help with experimental procedures.

\section{CONFLICTS OF INTEREST}

Prof. Dr. Dario Neri is co-founder and shareholder of Philogen, a biotech company having exclusive rights on the L19 antibody. Mr. Tiziano Ongaro, Mr. Baptiste Gouyou, Mr. Riccardo Corbellari and Dr. Alessandra Villa are employees of Philochem AG, a daughter company of Philogen. Mr. Marco Stringhini is a student at ETH 
Zurich. The authors have no additional financial interests to disclose. A patent covering L19L19-IL2 has been filed [WO/2020/070150].

\section{FUNDING}

We gratefully acknowledge funding from the European Research Council.

\section{REFERENCES}

1. Robert C, Ribas A, Wolchok JD, Hodi FS, Hamid O, Kefford R, Weber JS, Joshua AM, Hwu WJ, Gangadhar TC, Patnaik A, Dronca R, Zarour H, et al. Anti-programmeddeath-receptor-1 treatment with pembrolizumab in ipilimumab-refractory advanced melanoma: a randomised dose-comparison cohort of a phase 1 trial. Lancet. 2014; 384:1109-1117. https://doi.org/10.1016/S01406736(14)60958-2. [PubMed]

2. Brahmer JR, Tykodi SS, Chow LQ, Hwu WJ, Topalian SL, Hwu P, Drake CG, Camacho LH, Kauh J, Odunsi K, Pitot HC, Hamid O, Bhatia S, et al. Safety and activity of anti-PD-L1 antibody in patients with advanced cancer. N Engl J Med. 2012; 366:2455-2465. https://doi.org/10.1056/ NEJMoa1200694. [PubMed]

3. Topalian SL, Hodi FS, Brahmer JR, Gettinger SN, Smith DC, McDermott DF, Powderly JD, Carvajal RD, Sosman JA, Atkins MB, Leming PD, Spigel DR, Antonia SJ, et al. Safety, activity, and immune correlates of anti-PD-1 antibody in cancer. N Engl J Med. 2012; 366:2443-2454. https://doi.org/10.1056/NEJMoa1200690. [PubMed]

4. Pardoll DM. The blockade of immune checkpoints in cancer immunotherapy. Nat Rev Cancer. 2012; 12:252-264. https:// doi.org/10.1038/nrc3239. [PubMed]

5. Puca E, Probst P, Stringhini M, Murer P, Pellegrini G, Cazzamalli S, Hutmacher C, Gouyou B, Wulhfard S, Matasci M, Villa A, Neri D. The antibody-based delivery of interleukin-12 to solid tumors boosts $\mathrm{NK}$ and $\mathrm{CD} 8(+) \mathrm{T}$ cell activity and synergizes with immune checkpoint inhibitors. Int J Cancer. 2020; 146:2518-2530. https://doi.org/10.1002/ ijc.32603. [PubMed]

6. Corbellari R, Nadal L, Villa A, Neri D, De Luca R. The immunocytokine L19-TNF eradicates sarcomas in combination with chemotherapy agents or with immune check-point inhibitors. Anticancer Drugs. 2020; 31:799-805. https://doi.org/10.1097/CAD.0000000000000938. [PubMed]

7. Rekers NH, Zegers CM, Yaromina A, Lieuwes NG, Biemans R, Senden-Gijsbers BL, Losen M, Van Limbergen EJ, Germeraad WT, Neri D, Dubois L, Lambin P. Combination of radiotherapy with the immunocytokine L19-IL2: Additive effect in a NK cell dependent tumour model. Radiother Oncol. 2015; 116:438-442. https://doi. org/10.1016/j.radonc.2015.06.019. [PubMed]

8. Seung SK, Curti BD, Crittenden M, Walker E, Coffey T, Siebert JC, Miller W, Payne R, Glenn L, Bageac A, Urba
WJ. Phase 1 study of stereotactic body radiotherapy and interleukin-2-tumor and immunological responses. Sci Transl Med. 2012; 4:137ra74. https://doi.org/10.1126/ scitranslmed.3003649. [ubMed]

9. Pretto F, Elia G, Castioni N, Neri D. Preclinical evaluation of IL2-based immunocytokines supports their use in combination with dacarbazine, paclitaxel and TNF-based immunotherapy. Cancer Immunol Immunother. 2014; 63:901-910. https://doi.org/10.1007/s00262-014-1562-7. [PubMed]

10. Klapper JA, Downey SG, Smith FO, Yang JC, Hughes MS, Kammula US, Sherry RM, Royal RE, Steinberg SM, Rosenberg S. High-dose interleukin-2 for the treatment of metastatic renal cell carcinoma: a retrospective analysis of response and survival in patients treated in the surgery branch at the National Cancer Institute between 1986 and 2006. Cancer. 2008; 113:293-301. https://doi.org/10.1002/ cncr.23552. [PubMed]

11. Rosenberg SA. IL-2: the first effective immunotherapy for human cancer. J Immunol. 2014; 192:5451-5458. https:// doi.org/10.4049/jimmunol.1490019. [PubMed]

12. Charych DH, Hoch U, Langowski JL, Lee SR, Addepalli MK, Kirk PB, Sheng D, Liu X, Sims PW, VanderVeen LA, Ali CF, Chang TK, Konakova M, et al. NKTR-214, an Engineered Cytokine with Biased IL2 Receptor Binding, Increased Tumor Exposure, and Marked Efficacy in Mouse Tumor Models. Clin Cancer Res. 2016; 22:680-690. https:// doi.org/10.1158/1078-0432.CCR-15-1631. [PubMed]

13. Bukowski RM, Young J, Goodman G, Meyers F, Issell BF, Sergi JS, McLain D, Fyfe G, Finke J. Polyethylene glycol conjugated interleukin-2: clinical and immunologic effects in patients with advanced renal cell carcinoma. Invest New Drugs. 1993; 11:211-217. https://doi.org/10.1007/ BF00874158. [PubMed]

14. Dufour G. THOR-707, an engineered not-alpha IL-2, for the treatment of solid tumors induces strong immunological responses in vivo. CSCO Immunotherapy Seminar. (Shanghai, China). 2019.

15. Bentebibel SE, Hurwitz ME, Bernatchez C, Haymaker C, Hudgens CW, Kluger HM, Tetzlaff MT, Tagliaferri MA, Zalevsky J, Hoch U, Fanton C, Aung S, Hwu P, et al. A First-in-Human Study and Biomarker Analysis of NKTR214, a Novel IL2Rbetagamma-Biased Cytokine, in Patients with Advanced or Metastatic Solid Tumors. Cancer Discov. 2019; 9:711-721. https://doi.org/10.1158/2159-8290.CD18-1495. [PubMed]

16. Hurwitz ME. Abstract 2623: Baseline Tumor-Immune Signatures Associated with Response to Bempegaldesleukin (NKTR-214) and Nivolumab. Chicago, IL: ASCO; 2019. https:// doi.org/10.1200/jco.2019.37.15 suppl.2623.

17. Diab A, Tannir NM, Bentebibel SE, Hwu P, Papadimitrakopoulou V, Haymaker C, Kluger HM, Gettinger SN, Sznol M, Tykodi SS, Curti BD, Tagliaferri MA, Zalevsky J, et al. Bempegaldesleukin (NKTR-214) plus Nivolumab in Patients with Advanced Solid Tumors: 
Phase I Dose-Escalation Study of Safety, Efficacy, and Immune Activation (PIVOT-02). Cancer Discov. 2020; 10:1158-1173. https://doi.org/10.1158/2159-8290.CD-191510. [PubMed]

18. Arenas-Ramirez N, Zou C, Popp S, Zingg D, Brannetti B, Wirth E, Calzascia T, Kovarik J, Sommer L, Zenke G, Woytschak J, Regnier CH, Katopodis A, et al. Improved cancer immunotherapy by a CD25-mimobody conferring selectivity to human interleukin-2. Sci Transl Med. 2016; 8:367ra166. https://doi.org/10.1126/scitranslmed.aag3187. [PubMed]

19. Silva DA, Yu S, Ulge UY, Spangler JB, Jude KM, LabaoAlmeida C, Ali LR, Quijano-Rubio A, Ruterbusch M, Leung I, Biary T, Crowley SJ, Marcos E, et al. De novo design of potent and selective mimics of IL-2 and IL15. Nature. 2019; 565:186-191. https://doi.org/10.1038/ s41586-018-0830-7. [PubMed]

20. Savage P, So A, Spooner RA, Epenetos AA. A recombinant single chain antibody interleukin-2 fusion protein. $\mathrm{Br}$ J Cancer. 1993; 67:304-310. https://doi.org/10.1038/ bjc.1993.57. [PubMed]

21. Klein C, Waldhauer I, Nicolini VG, FreimoserGrundschober A, Nayak T, Vugts DJ, Dunn C, Bolijn M, Benz J, Stihle M, Lang S, Roemmele M, Hofer T, et al. Cergutuzumab amunaleukin (CEA-IL2v), a CEA-targeted IL-2 variant-based immunocytokine for combination cancer immunotherapy: Overcoming limitations of aldesleukin and conventional IL-2-based immunocytokines. Oncoimmunology. 2017; 6:e1277306. https://doi.org/10.10 80/2162402X.2016.1277306. [PubMed]

22. Albertini MR, Hank JA, Gadbaw B, Kostlevy J, Haldeman J, Schalch H, Gan J, Kim K, Eickhoff J, Gillies SD, Sondel PM. Phase II trial of hu14.18-IL2 for patients with metastatic melanoma. Cancer Immunol Immunother. 2012; 61:2261-2271. https://doi.org/10.1007/s00262-012-1286-5. [PubMed]

23. Carnemolla B, Borsi L, Balza E, Castellani P, Meazza R, Berndt A, Ferrini S, Kosmehl H, Neri D, Zardi L. Enhancement of the antitumor properties of interleukin-2 by its targeted delivery to the tumor blood vessel extracellular matrix. Blood. 2002; 99:1659-1665. https:// doi.org/10.1182/blood.V99.5.1659. [PubMed]

24. Frey K, Schliemann C, Schwager K, Giavazzi R, Johannsen M, Neri D. The immunocytokine F8-IL2 improves the therapeutic performance of sunitinib in a mouse model of renal cell carcinoma. J Urol. 2010; 184:2540-2548. https:// doi.org/10.1016/i.juro.2010.07.030. [PubMed]

25. Marlind J, Kaspar M, Trachsel E, Sommavilla R, Hindle S, Bacci C, Giovannoni L, Neri D. Antibody-mediated delivery of interleukin-2 to the stroma of breast cancer strongly enhances the potency of chemotherapy. Clin Cancer Res. 2008; 14:6515-6524. https://doi.org/10.1158/1078-0432. CCR-07-5041. [PubMed]

26. Gillies SD. A new platform for constructing antibodycytokine fusion proteins (immunocytokines) with improved biological properties and adaptable cytokine activity. Protein Eng Des Sel. 2013; 26:561-569. https://doi. org/10.1093/protein/gzt045. [PubMed]

27. Pini A, Viti F, Santucci A, Carnemolla B, Zardi L, Neri P, Neri D. Design and use of a phage display library. Human antibodies with subnanomolar affinity against a marker of angiogenesis eluted from a two-dimensional gel. J Biol Chem. 1998; 273:21769-21776. https://doi.org/10.1074/ ibc.273.34.21769. [PubMed]

28. Zardi L, Carnemolla B, Siri A, Petersen TE, Paolella G, Sebastio G, Baralle FE. Transformed human cells produce a new fibronectin isoform by preferential alternative splicing of a previously unobserved exon. EMBO J. 1987; 6:23372342. https://doi.org/10.1002/j.1460-2075.1987.tb02509.x. [PubMed]

29. Carnemolla B, Balza E, Siri A, Zardi L, Nicotra MR, Bigotti A, Natali PG. A tumor-associated fibronectin isoform generated by alternative splicing of messenger RNA precursors. J Cell Biol. 1989; 108:1139-1148. https://doi. org/10.1083/jcb.108.3.1139. [PubMed]

30. Castellani P, Viale G, Dorcaratto A, Nicolo G, Kaczmarek J, Querze G, Zardi L. The fibronectin isoform containing the ED-B oncofetal domain: a marker of angiogenesis. Int J Cancer. 1994; 59:612-618. https://doi.org/10.1002/ ijc.2910590507. [PubMed]

31. Tarli L, Balza E, Viti F, Borsi L, Castellani P, Berndorff D, Dinkelborg L, Neri D, Zardi L. A high-affinity human antibody that targets tumoral blood vessels. Blood. 1999; 94:192-198. https://doi.org/10.1182/blood. V94.1.192.413k22 192 198. [PubMed]

32. Viti F, Tarli L, Giovannoni L, Zardi L, Neri D. Increased binding affinity and valence of recombinant antibody fragments lead to improved targeting of tumoral angiogenesis. Cancer Res. 1999; 59:347-352. [PubMed]

33. Tijink BM, Neri D, Leemans CR, Budde M, Dinkelborg LM, Stigter-van Walsum M, Zardi L, van Dongen GA. Radioimmunotherapy of head and neck cancer xenografts using 131I-labeled antibody L19-SIP for selective targeting of tumor vasculature. J Nucl Med. 2006; 47:1127-1135. [PubMed]

34. Erba PA, Sollini M, Orciuolo E, Traino C, Petrini M, Paganelli G, Bombardieri E, Grana C, Giovannoni L, Neri D, Menssen HD, Mariani G. Radioimmunotherapy with radretumab in patients with relapsed hematologic malignancies. J Nucl Med. 2012; 53:922-927. https://doi. org/10.2967/jnumed.111.101006. [PubMed]

35. Poli GL, Bianchi C, Virotta G, Bettini A, Moretti R, Trachsel E, Elia G, Giovannoni L, Neri D, Bruno A. Radretumab radioimmunotherapy in patients with brain metastasis: a 124I-L19SIP dosimetric PET study. Cancer Immunol Res. 2013; 1:134-143. https://doi.org/10.1158/2326-6066.CIR13-0007. [PubMed]

36. Holliger P, Prospero T, Winter G. "Diabodies": small bivalent and bispecific antibody fragments. Proc Natl Acad Sci U S A. 1993; 90:6444-6448. https://doi.org/10.1073/ pnas.90.14.6444. [PubMed] 
37. Schliemann C, Palumbo A, Zuberbuhler K, Villa A, Kaspar M, Trachsel E, Klapper W, Menssen HD, Neri D. Complete eradication of human B-cell lymphoma xenografts using rituximab in combination with the immunocytokine L19IL2. Blood. 2009; 113:2275-2283. https://doi.org/10.1182/ blood-2008-05-160747. [PubMed]

38. Schwager K, Hemmerle T, Aebischer D, Neri D. The immunocytokine L19-IL2 eradicates cancer when used in combination with CTLA-4 blockade or with L19TNF. J Invest Dermatol. 2013; 133:751-758. https://doi. org/10.1038/jid.2012.376. [PubMed]

39. Malyala P, Singh M. Endotoxin limits in formulations for preclinical research. J Pharm Sci. 2008; 97:2041-2044. https://doi.org/10.1002/jps.21152. [PubMed]

40. Skrombolas D, Frelinger JG. Challenges and developing solutions for increasing the benefits of IL-2 treatment in tumor therapy. Expert Rev Clin Immunol. 2014; 10:207217. https://doi.org/10.1586/1744666X.2014.875856. [PubMed]

41. Klatzmann D, Abbas AK. The promise of low-dose interleukin-2 therapy for autoimmune and inflammatory diseases. Nat Rev Immunol. 2015; 15:283-294. https://doi. org/10.1038/nri3823. [PubMed]

42. Koreth J, Matsuoka K, Kim HT, McDonough SM, Bindra B, Alyea EP 3rd, Armand P, Cutler C, Ho VT, Treister NS, Bienfang DC, Prasad S, Tzachanis D, et al. Interleukin-2 and regulatory $\mathrm{T}$ cells in graft-versus-host disease. N Engl J Med. 2011; 365:2055-2066. https://doi.org/10.1056/ NEJMoa1108188. [PubMed]

43. He J, Zhang X, Wei Y, Sun X, Chen Y, Deng J, Jin Y, Gan Y, Hu X, Jia R, Xu C, Hou Z, Leong YA, et al. Low-dose interleukin-2 treatment selectively modulates CD4(+) T cell subsets in patients with systemic lupus erythematosus. Nat Med. 2016; 22:991-993. https://doi.org/10.1038/nm.4148. [PubMed]

44. Saadoun D, Rosenzwajg M, Joly F, Six A, Carrat F, Thibault V, Sene D, Cacoub P, Klatzmann D. Regulatory T-cell responses to low-dose interleukin-2 in HCV-induced vasculitis. N Engl J Med. 2011; 365:2067-2077. https://doi. org/10.1056/NEJMoa1105143. [PubMed]

45. Arce Vargas F, Furness AJS, Solomon I, Joshi K, Mekkaoui L, Lesko MH, Miranda Rota E, Dahan R, Georgiou A, Sledzinska A, Ben Aissa A, Franz D, Werner Sunderland M, et al. Fc-Optimized Anti-CD25 Depletes TumorInfiltrating Regulatory T Cells and Synergizes with PD-1 Blockade to Eradicate Established Tumors. Immunity. 2017; 46:577-586. https://doi.org/10.1016/j.immuni.2017.03.013. [PubMed]

46. Wei SC, Duffy CR, Allison JP. Fundamental Mechanisms of Immune Checkpoint Blockade Therapy. Cancer Discov. 2018; 8:1069-1086. https://doi.org/10.1158/2159-8290.CD18-0367. [PubMed]

47. Hutmacher C, Gonzalo Nunez N, Liuzzi AR, Becher B, Neri D. Targeted Delivery of IL2 to the Tumor Stroma Potentiates the Action of Immune Checkpoint Inhibitors by Preferential Activation of NK and CD8(+) T Cells. Cancer Immunol Res. 2019; 7:572-583. https://doi. org/10.1158/2326-6066.CIR-18-0566. [PubMed]

48. Sharma M, Khong H, Fa'ak F, Bentebibel SE, Janssen LME, Chesson BC, Creasy CA, Forget MA, Kahn LMS, Pazdrak B, Karki B, Hailemichael Y, Singh M, et al. Bempegaldesleukin selectively depletes intratumoral Tregs and potentiates T cell-mediated cancer therapy. Nat Commun. 2020; 11:661. https://doi.org/10.1038/s41467020-14471-1. [PubMed]

49. Prieto PA, Yang JC, Sherry RM, Hughes MS, Kammula US, White DE, Levy CL, Rosenberg SA, Phan GQ. CTLA4 blockade with ipilimumab: long-term follow-up of 177 patients with metastatic melanoma. Clin Cancer Res. 2012; 18:2039-2047. https://doi.org/10.1158/1078-0432.CCR-111823. [PubMed]

50. Maker AV, Phan GQ, Attia P, Yang JC, Sherry RM, Topalian SL, Kammula US, Royal RE, Haworth LR, Levy C, Kleiner D, Mavroukakis SA, Yellin M, et al. Tumor regression and autoimmunity in patients treated with cytotoxic $\mathrm{T}$ lymphocyte-associated antigen 4 blockade and interleukin 2: a phase I/II study. Ann Surg Oncol. 2005; 12:1005-1016. https://doi.org/10.1245/ASO.2005.03.536. [PubMed]

51. Probst P, Stringhini M, Ritz D, Fugmann T, Neri D. Antibody-based Delivery of TNF to the Tumor Neovasculature Potentiates the Therapeutic Activity of a Peptide Anticancer Vaccine. Clin Cancer Res. 2019; 25:698-709. https://doi.org/10.1158/1078-0432.CCR-181728. [PubMed]

52. Johannsen M, Spitaleri G, Curigliano G, Roigas J, Weikert S, Kempkensteffen C, Roemer A, Kloeters C, Rogalla P, Pecher G, Miller K, Berndt A, Kosmehl H, et al. The tumourtargeting human L19-IL2 immunocytokine: preclinical safety studies, phase I clinical trial in patients with solid tumours and expansion into patients with advanced renal cell carcinoma. Eur J Cancer. 2010; 46:2926-2935. https:// doi.org/10.1016/j.ejca.2010.07.033. [PubMed]

53. Weide B, Eigentler T, Catania C, Ascierto PA, Cascinu S, Becker JC, Hauschild A, Romanini A, Danielli R, Dummer R, Trefzer U, Elia G, Neri D, et al. A phase II study of the L19IL2 immunocytokine in combination with dacarbazine in advanced metastatic melanoma patients. Cancer Immunol Immunother. 2019; 68:1547-1559. https://doi.org/10.1007/ s00262-019-02383-z. [PubMed]

54. Eigentler TK, Weide B, de Braud F, Spitaleri G, Romanini A, Pflugfelder A, Gonzalez-Iglesias R, Tasciotti A, Giovannoni L, Schwager K, Lovato V, Kaspar M, Trachsel $\mathrm{E}$, et al. A dose-escalation and signal-generating study of the immunocytokine L19-IL2 in combination with dacarbazine for the therapy of patients with metastatic melanoma. Clin Cancer Res. 2011; 17:7732-7742. https:// doi.org/10.1158/1078-0432.CCR-11-1203. [PubMed] 